\title{
BOD:COD Ratio as an Indicator for Pollutants Leaching from Landfill
}

\author{
Aik Heng Lee and Hamid Nikraz
}

\begin{abstract}
The relationship of BOD to COD of leachate from a mature landfill site are investigated over a period of six years to determine the indicator to be used for prediction of leachate characteristic generating from landfill site. Results of the investigation reveal that BOD:COD ratio is a good indicator of degradation of organic matter in landfill. It can be used as an indicator for degradation of organic matter that differentiate the acetogenic phase from methanogenic phase in this landfill
\end{abstract}

Index Terms-BOD:COD ratio, landfill leachate, waste decomposition.

\section{INTRODUCTION}

Leachate is the percolation liquid that drains through the waste in the landfill that varies widely depend on landfill content and climatic condition [1]-[9]. In landfill leachate, many chemicals may be represented as organic matters, inorganic matters and xenobiotic organic compounds.

Organic matters are usually quantified as BOD (Biochemical Oxygen Demand) and COD (Chemical Oxygen Demand) while inorganic matters are mainly quantified as sulfate, chloride, ammonium, heavy metals and others.

The organic matters are organic molecules of varied origin and composition in leachate that are measured in terms of BOD and COD.

Both BOD and COD are commonly used to measure organic matter content in leachate with some reporting BOD and COD values of 20 to $57,000 \mathrm{mg} / \mathrm{L}$ and 140 to 15200 $\mathrm{mg} / \mathrm{L}$ respectively [5]-[8]. It is anticipated that BOD and COD value decrease over time most likely attribute to a combination of reduction of organic pollutants that are leaching in the landfill.

The purpose of this study is to determine the use of BOD:COD ratio as an indicator to characterize pollutant leaching from landfill.

\section{MATERIAL AND METHOD}

The leachate data used in this study is obtained from the performance results of a landfill site at Toronto over a period of 6 (six) years spread from 2004 to 2009. The leachate composition is typical of a mature landfill. The landfill is deposited with wastes of solid, non-hazardous, industrial, commercial and institutional waste from municipalities and business.

Manuscript received June 6, 2013; revised July 18, 2013.

The authors are with Civil Engineering Department, Curtin University, Australia (e-mail: lah@yesenviro.com,H.Nikraz@curtin.edu.au).
The characteristics of leachate are evaluated in terms of BOD, COD, TKN (Total Kjeldahl Nitrogen), ammonia, nitrite and nitrate. Other parameters such as calcium, chloride, iron, magnesium, sodium sulfate and xenobiotic organic compounds such as phenols are also evaluated.

\section{RESUlts AND Discussion}

Duration of waste placement in landfill determines the extent of microbial activity that affect the quality of leachate. As BOD is predominantly a biochemical parameter, it generally reflects biodegradability of organic matter in leachate thus making BOD:COD ratio a good indicator of the proportion of biochemically degradable organic matter to total organic matter. Thus BOD:COD ratio is typically a measurement used to describe the organic composition in the leachate and it appears to be a good representation of waste stabilization transiting from early acetogenic phase to mature methanogenic phase in landfill. Due to variability of waste placement, it is useful to determine the relationship of BOD:COD ratio and leachate quality generating from the landfill.

Fig. 1 depicts the ratio of BOD:COD spread over the six years in the landfill studied.

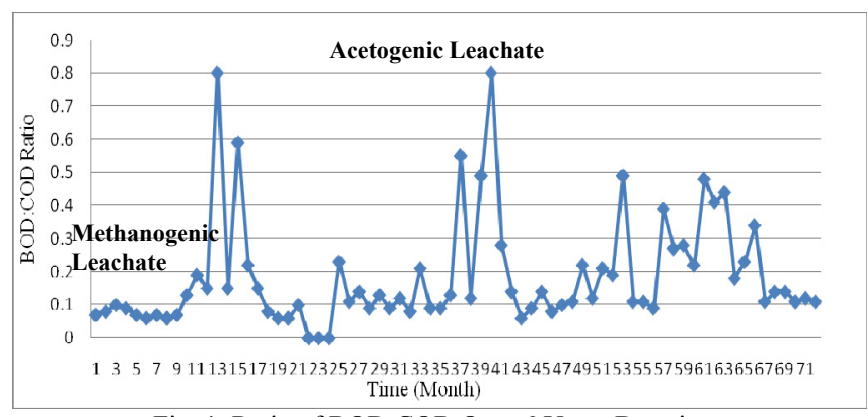

Fig. 1. Ratio of BOD:COD Over 6 Years Duration

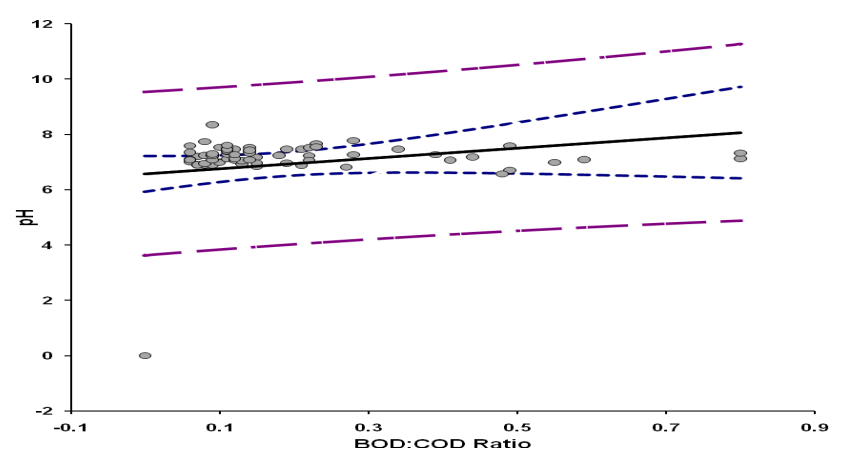

Fig. 2. pH of Leachate Versus BOD:COD Ratio

Fig. 2 depicts the correlations of $\mathrm{pH}$ to BOD:COD of 
leachate with an equation of $\mathbf{p H}=\mathbf{6 . 5 7 9}+\mathbf{1 . 8 6 1}$ BOD:COD. The $\mathrm{r}^{2}$ value show $40 \%$ of the total variation about the BOD:COD mean is explained by the regression line. The confidence interval for the slope shows that with $95 \%$ confidence the data value for the slope line somewhere between 6.085 and 7.092 .

Fig. 3 depicts the alkalinity to BOD:COD of leachate with an equation of Alkalinity $=\mathbf{2 5 3 9}-\mathbf{5 6 2 . 1}$ BOD:COD. The $\mathrm{r}^{2}$ value of $1 \%$ is obtained and the $95 \%$ confident interval lies between 2214 and 2863 .

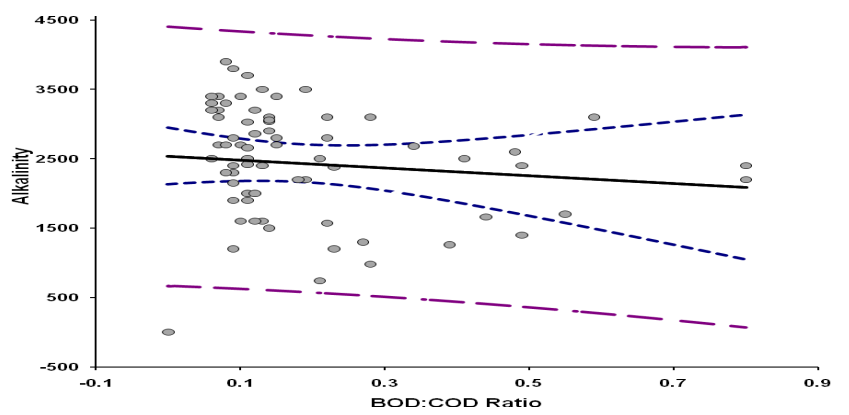

Fig. 3. Alkalinity of Leachate Versus BOD:COD Ratio

Fig. 4 shows the hardness to BOD:COD of leachate with an equation of Hardness $=775.1+1212$ BOD:COD. The $\mathrm{r}^{2}$ value of $17 \%$ is obtained and the $95 \%$ confident interval lies between 615.2 and 934.9 .

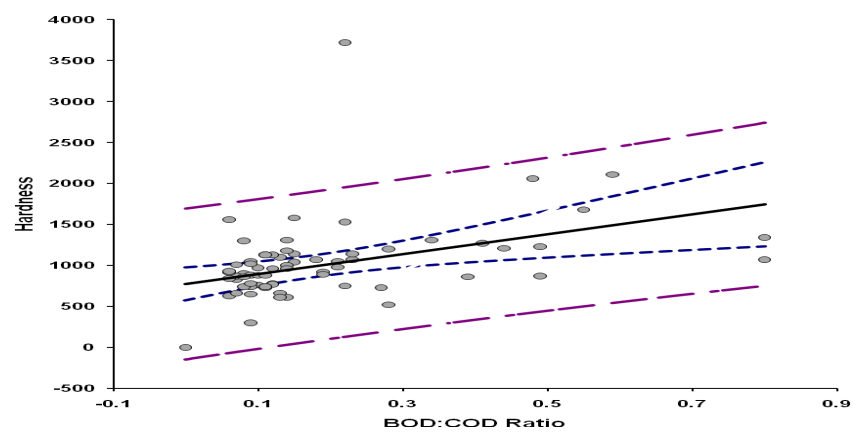

Fig. 4. Hardness of Leachate Versus BOD:COD Ratio

Fig. 5 illustrates the conductivity to BOD:COD leachate with an equation of Conductivity $=\mathbf{6 8 9 0}+\mathbf{3 8 5 0}$ BOD:COD The $r^{2}$ value of $1 \%$ is obtained and the $95 \%$ confident interval lies between 4190 and 9189 .

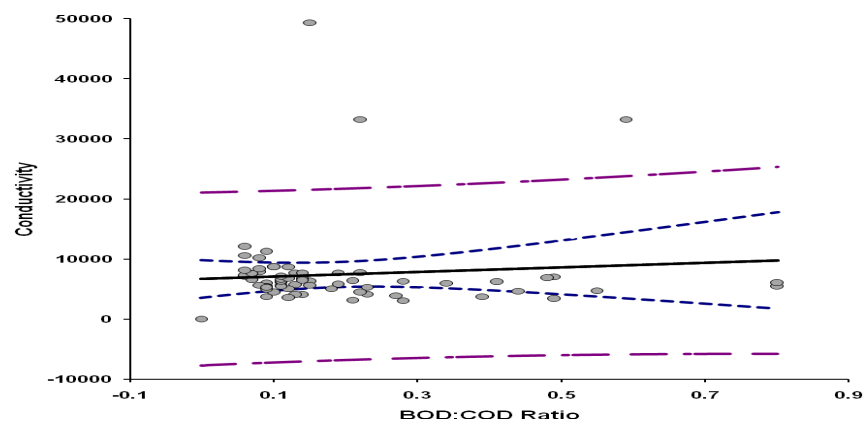

Fig. 5. Conductivity of Leachate Versus BOD:COD Ratio

The correlation of total suspended solids to BOD:COD of leachate is depicted in Fig. 6 with an equation Total Suspended Solids $=\mathbf{5 0 . 0 4}+\mathbf{7 2 . 2 4}$ BOD:COD. The $\mathrm{r}^{2}$ value of $1 \%$ and the $95 \%$ confident interval lies between 2.23 and 97.84 .

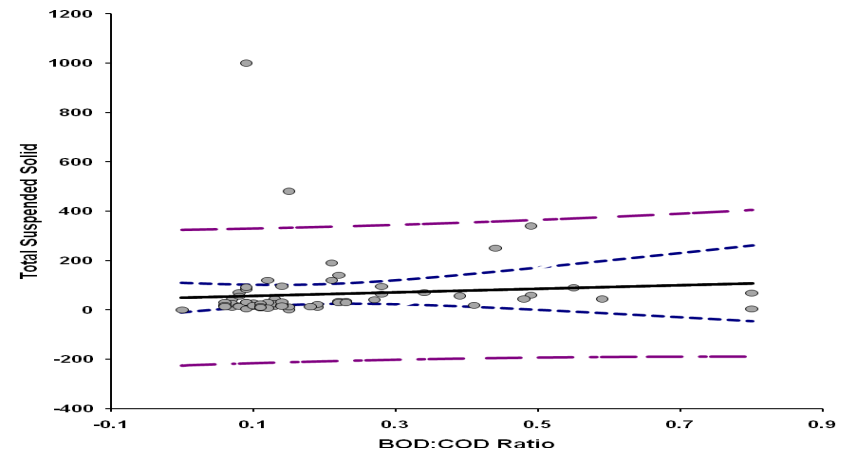

Fig. 6. Total Suspended Solid of Leachate Versus BOD:COD Ratio

Fig. 7 depicts BOD to BOD:COD of leachate with an equation BOD $=\mathbf{1 5 2}+\mathbf{2 1 2 0}$ BOD:COD. The $r^{2}$ value of $51 \%$ is obtained and the $95 \%$ confidence interval lies between -275.4 and $-29.7 \mathrm{mg} / \mathrm{l}$.

The correlation of COD and DOC to BOD:COD of leachate are depicted in Fig. 8 and Fig. 9 with equations of COD $=481.3+2505$ BOD: $C O D$ and $D O C=207.2+541.6$ BOD:COD. The $\mathrm{r}^{2}$ value of $25 \%$ and $13 \%$ with the $95 \%$ confidence interval spreads between 223.2 and $739.4 \mathrm{mg} / \mathrm{l}$ and 125.9 and $288.4 \mathrm{mg} / \mathrm{l}$ respectively.

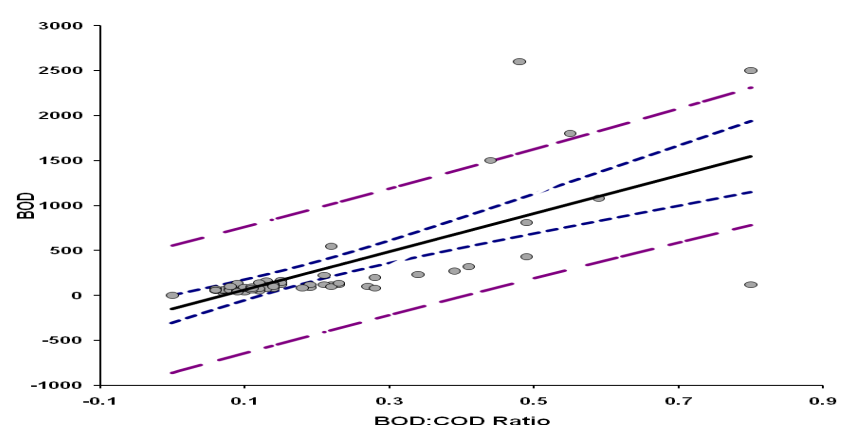

Fig. 7. BOD of Leachate Versus BOD:COD Ratio

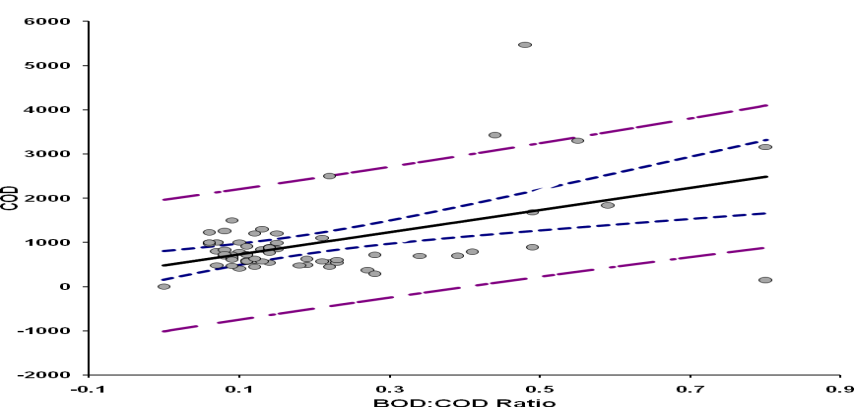

Fig. 8. COD of Leachate Versus BOD:COD Ratio

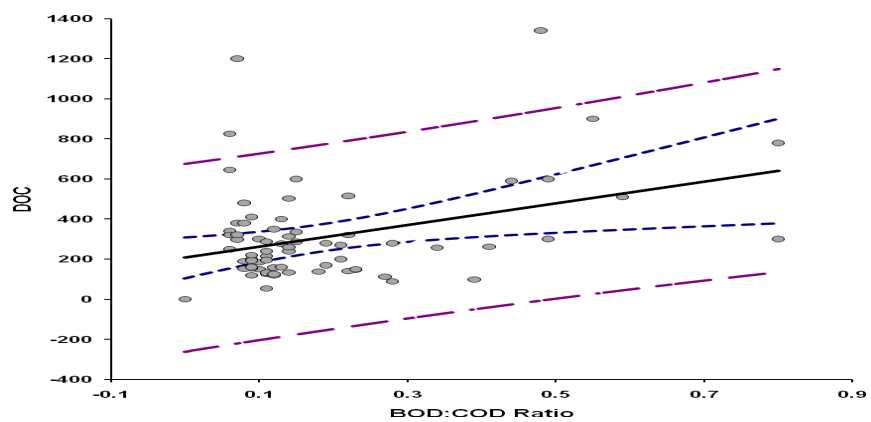

Fig. 9. DOC of Leachate Versus BOD:COD Ratio

Fig. 10 depicts the correlation of Sulphate to BOD:COD of leachate with an equation of Sulphate $=\mathbf{3 7 . 5 1}+\mathbf{2 2 0 . 8}$ 
BOD:COD. The $r^{2}$ value of $11 \%$ is obtained and the $95 \%$ confident interval spread from 0.66 to $74.36 \mathrm{mg} / 1$.

Fig. 11 depicts to correlation of chloride to BOD:COD ratio of leachate with an equation of Chloride $=\mathbf{6 8 3 . 2}$ 130.6 BOD:COD. The $r^{2}$ value of $1 \%$ is obtained and the $95 \%$ confident interval spread between 593.6 and $772.9 \mathrm{mg} / \mathrm{l}$. Negative correlation achieved reveals that there is an inverse relationship of lower chloride value at higher BOD:COD ratio.

The correlation of ammonia to BOD:COD of leachate is depicted in Fig. 12 with an equation of Ammonia = 250.6 117.2 BOD:COD. The $r^{2}$ value of $4 \%$ is obtained and the 95\% confident interval lied somewhere between 216.2 and $283.0 \mathrm{mg} / \mathrm{l}$.

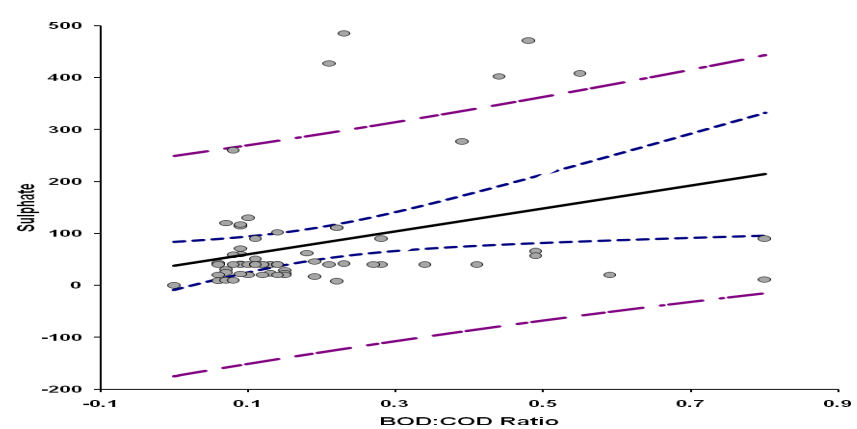

Fig. 10. Sulphate of Leachate Versus BOD:COD Ratio

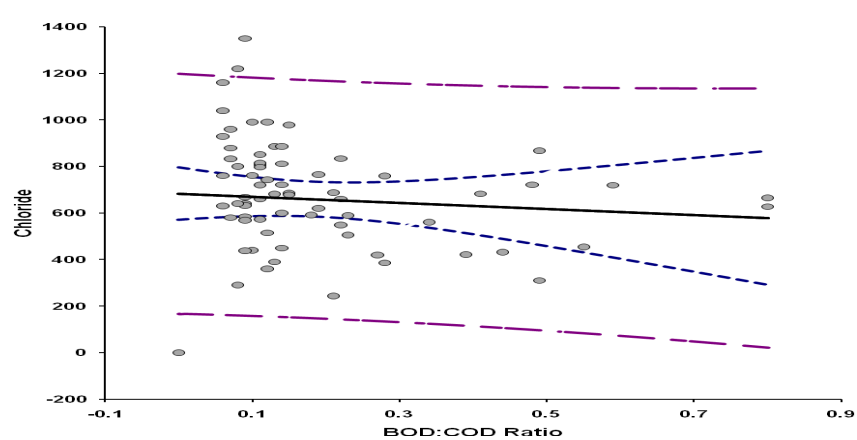

Fig. 11. Chloride of Leachate Versus BOD:COD Ratio

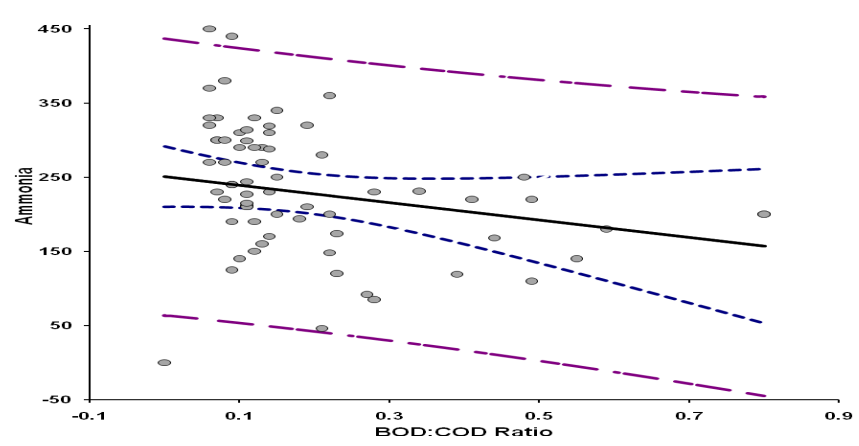

Fig. 12. Ammonia of Leachate Versus BOD:COD Ratio

Fig. 13 depicts the correlation of calcium to BOD:COD ratio of leachate with an equation of Calcium $=\mathbf{1 3 8 . 7}+\mathbf{4 1 3}$ BOD:COD. The $\mathrm{r}^{2}$ value of $21 \%$ is obtained and the $95 \%$ confidence interval spreads between 91.5 and $186.0 \mathrm{mg} / \mathrm{l}$.

Fig. 14 illustrates the correlation of magnesium to BOD:COD of leachate with an equation of Magnesium = 102.5 + 42.13 BOD:COD. The $r^{2}$ value obtained is $3 \%$ and the $95 \%$ confident interval lies between 87.5 and $117.4 \mathrm{mg} / 1$.

Fig. 15 depicts the correlation of sodium to BOD:COD ratio of leachate with an equation of Sodium $=\mathbf{6 3 5 . 8}-156$
BOD:COD. The $\mathrm{r}^{2}$ value of $1 \%$ is obtained and the $95 \%$ confident interval lies between 544.1 and $727.8 \mathrm{mg} / \mathrm{l}$. Negative correlation reveals that there is an inverse relationship of lower sodium at higher BOD:COD.

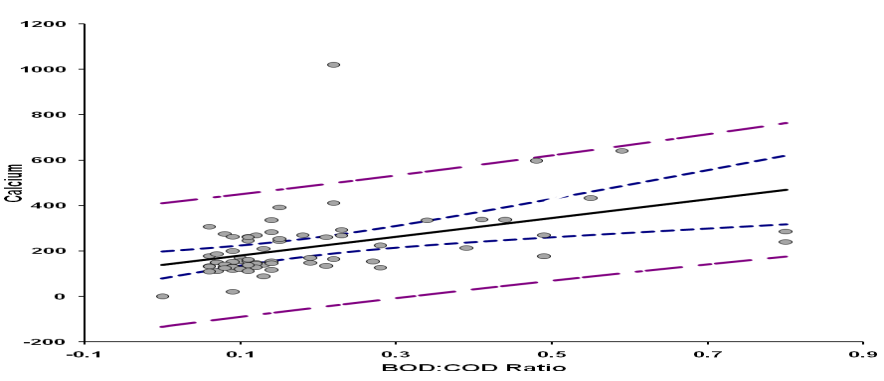

Fig. 13. Calcium of Leachate Versus BOD:COD Ratio

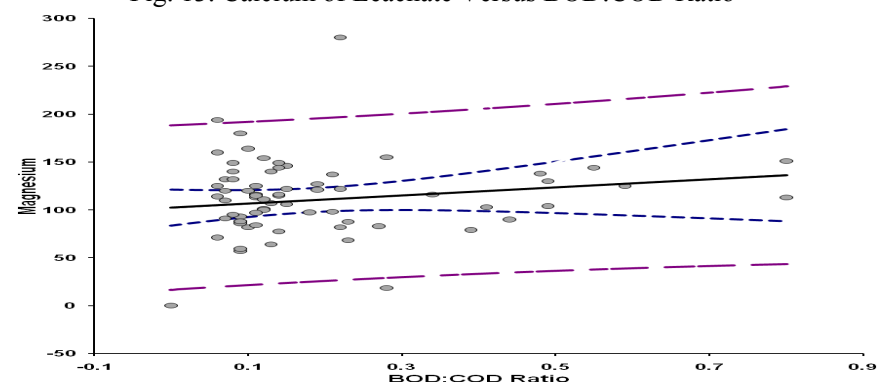

Fig. 14. Magnesium of Leachate Versus BOD:COD Ratio

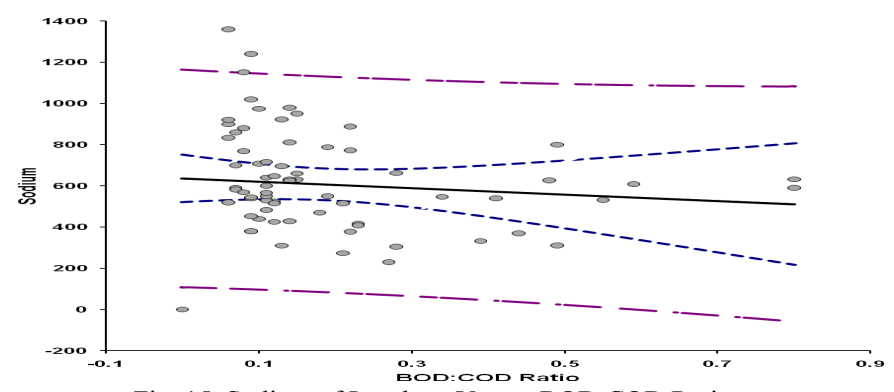

Fig. 15. Sodium of Leachate Versus BOD:COD Ratio

Fig. 16 Illustrates the correlation of iron to BOD:COD ratio of leachate with an equation of Iron $=\mathbf{7 . 1 4 3}+\mathbf{9 . 8 0 7}$ BOD:COD. The $\mathrm{r}^{2}$ value of $1 \%$ is obtained and the $95 \%$ confident interval spread between -2.896 and $17.181 \mathrm{mg} / \mathrm{l}$.

The correlations of Nitrate and Nitrite to BOD:COD ratio of leachate are depicts in Fig. 17 and Fig. 18 with equation of Nitrate $=1.216+0.6509$ BOD:COD and Nitrite $=1.301+$ 0.5375 BOD:COD of $2 \%$ and $2 \%$ with the $95 \%$ confident intervals spreads between 0.954 and $1.478 \mathrm{mg} / \mathrm{l}$ and 1.061 and $1.541 \mathrm{mg} / \mathrm{l}$ respectively.

Fig. 19 shows the correlation of TKN to BOD:COD ratio of leachate with an equation of TKN $=\mathbf{3 2 8 . 5}-\mathbf{1 5 2 . 4}$ BOD:COD. The $\mathrm{r}^{2}$ value of $4 \%$ is obtained and the $95 \%$ confident interval spreads between 281.5 and $375.5 \mathrm{mg} / \mathrm{l}$.

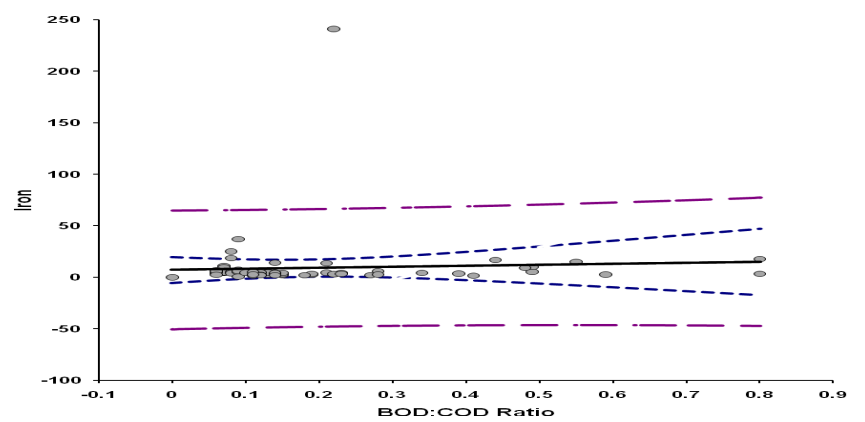

Fig. 16. Iron of Leachate Versus BOD:COD Ratio 


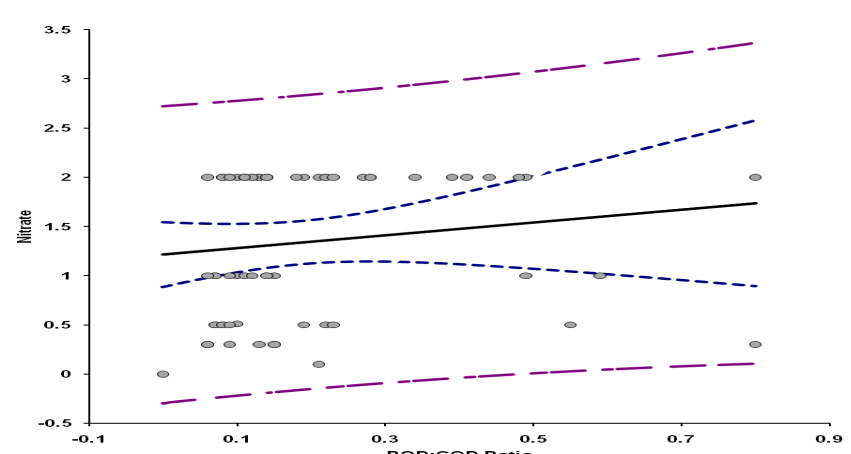

Fig. 17. Nitrate of Leachate Versus BOD:COD Ratio

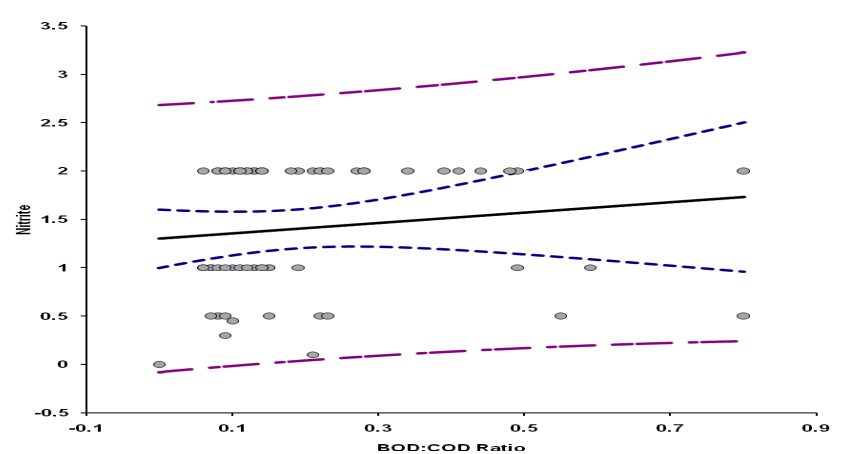

Fig. 18. Nitrite of Leachate Versus BOD:COD Ratio

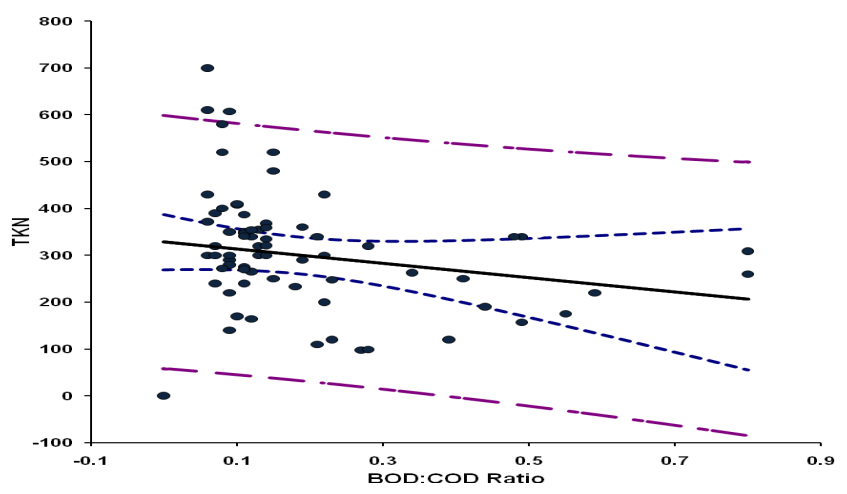

Fig. 19. TKN of Leachate Versus BOD:COD Ratio

Fig. 20 depicts the correlation of phenol to BOD:COD ratio of leachate with an equation of Phenol $=\mathbf{6 5 . 8 9}+\mathbf{7 8 7 . 7}$ BOD:COD. The $\mathrm{r}^{2}$ value of $43 \%$ is obtained and the $95 \%$ confident interval spreads between 12.03 and $119.73 \mathrm{mg} / \mathrm{l}$.

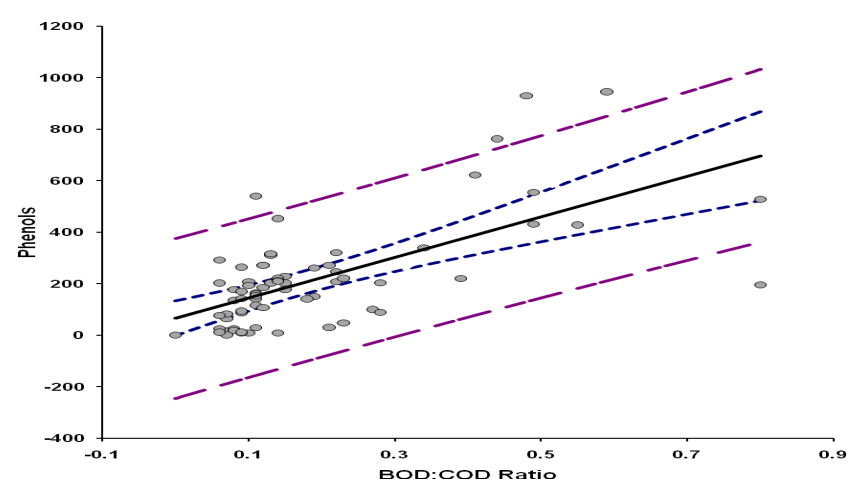

Fig. 20. Phenols of Leachate Versus BOD:COD Ratio

From the data evaluation as illustrated in Fig. 2 -Fig. 20, all physical properties $\left(r^{2}<0.4\right)$; all organic matters $\left(r^{2}<0.51\right)$; all inorganic matters $\left(\mathrm{r}^{2}<0.21\right)$ and xenobiotic organic compounds of phenol $\left(r^{2}<0.43\right)$ reveals that quality of leachate correlates well to waste age expressed in terms of BOD:COD ratio. This can be explained that microbial degradation depends greatly on the composition of both organic and inorganic constituents in the waste experiencing different exposure of acetogenic and methanogenic phases.

\section{CONCLUSION}

It is concluded that BOD:COD ratio is a good indicator for degrees of both biological and chemical decompositions that are taken place in the landfill and can be taken as an indicator of degradation of organic matter in landfill. It can be provided as useful information for the design and management of landfill leachate that made prediction more realistic for future trends.

\section{ACKNOWLEDGMENT}

A special acknowledgment of appreciation is given to $\mathrm{Mr}$. George South of City of Toronto Municipality for his assistance given.

\section{REFERENCES}

[1] T. W. Assumuth and T. Strandberg, "Ground-water contamination at Finnish landfills Water," Air Soil Pollut., vol. 69, pp. 179, 1993.

[2] A. M. Martensson, C. Aulin, O. Wahlberg, and S. Argen, "Effect of humic substances on the mobility of toxic metals in a mature landfill," Waste Manag. Res., vol. 17, pp. 296, 1999.

[3] M. Ritzkowski, K. U. Heyer, and R. Stegmann, "Insitute aeration of old landfills: Carbon balances, temperatures and settlements," in Proceedings of Sardia, 2003-Ninety International Waste Management and landfill Symposium, Cagliari, Italy, 2003, pp. 06-10.

[4] M. A. Barlaz, R. K. Ham, and D. M. Shaefer, "Methane Production from municipal refuse: A Review of enhancement techniques and microbial dynamics," CRC Crit. Rev. Environ. Contr., vol. 19, no. 6, pp. 557,1990

[5] E. S. K. Chian and F. B. DeWalle, "Characterization of soluble organic matter in leachate," Environ Sci. Techol., vol. 11, pp. 158, 1977.

[6] H. J. Ehrig, "Quality and quantity of sanitary landfill leachate," Waste Manag. Res., vol. 1, pp. 53, 1983.

[7] P. Kjeldsen and M. Christophersen, "Composition of leachate from old landfills in Denmark," Waste Manag. Res., vol. 19, pp. 24-256, 2001.

[8] P. Kjeldsen, M. Barlaz, A. Rooker, A. Baun, A. Ledin, and T. Christensen, 'Present and Long-Term Composition of MSW Landfill Leachate : A Review," Critical Reviews in Environmental Science and Technology, vol. 32, no. 4, pp. 297-336, 2002.

[9] A. O. Adeolu, A. V. Oriaku, G. A. Adewumi, and A. A. Otitoloju, "Assessment of groundwater contamination by leachate near a municipal solid waste landfill," Journal of Environmental Science and Technology, vol.5, no. 11, pp. 933-940, November 2011.

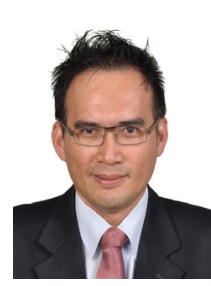

Aik Heng Lee is holding PhD, MSc and BSc degrees in Civil Engineering and is a research fellow of Civil Engineering Department, Curtin University, Australia. $\mathrm{He}$ has extensive experiences in research and development pertaining to environmental engineering technology. 